\title{
ATACADO E ATACAREJO COMO OPÇÃO DE COMPRA DE CLIENTES DE DISTRIBUIDORA DE ALIMENTOS
}

\author{
WHOLESALE AND “ATACAREJO” AS BUYING \\ OPTION TO CUSTOMERS OF FOOD \\ DISTRIBUTION
}

Recebido 30/09/2011

Aceito $16 / 02 / 2012$

Huang Wen Hsien ${ }^{1}$

Antonio Carlos Giuliani²

Christiano França da Cunha ${ }^{3}$

Nádia Kassouf Pizzinato ${ }^{4}$

\section{RESUMO}

Este artigo estuda canais de Marketing, tendo como objetivo principal avaliar os fatores que influenciam no processo decisório de compra de pequenas e médias empresas varejistas, entendendo o que leva os clientes a migrarem suas compras do atacado/distribuidor tradicional para o "atacarejo". O estudo corrobora com a atualização dos conceitos de canais de marketing e de comportamento de compra do cliente. A pesquisa foi feita com um estudo de caso. Os dados coletados foram analisados com o uso de um estudo exploratório e com o auxílio de análises quantitativas. Observa-se quais os principais fatores de influência na escolha do atacarejo e do atacado.

Palavras-chave: Marketing; Varejo; Canais de marketing; Comportamento do cliente; Processo decisório de compra.

\footnotetext{
${ }^{1}$ Mestre em Administração, Universidade Metodista de Piracicaba (UNIMEP), Piracicaba, São Paulo. Brasil. Email: huangbruno@yahoo. com.br

${ }^{2}$ Professor, Doutor, Universidade Metodista de Piracicaba (UNIMEP), Piracicaba, São Paulo, Brasil. Email: cgiuliani@unimep.br

${ }^{3}$ Professor, Doutor, Universidade Metodista de Piracicaba (UNIMEP) , Piracicaba, São Paulo, Brasil. Brasil. Email: chfcunha@unimep.br

${ }^{4}$ Professora, Doutora, Universidade Metodista de Piracicaba (UNIMEP), Piracicaba, São Paulo, Brasil. Brasil. Email: nkpizzinat@unimep.br
} 


\section{ABSTRACT}

This paper studies the marketing channels, being the main objective the evaluation of the factors that influence the purchase decision process of small and medium retailers, understanding what drives them to migrate its purchases in the traditional wholesale / distributor to "atacarejo". The study confirms the update of the concepts of marketing channels and customer purchasing behavior. The research was done using a case study. The data were analyzed using an exploratory study and quantitative analysis. It is observed that the main factors influencing the choice of atacarejo and wholesale.

Keywords: Marketing; Retail; Marketing channels; Customer behavior; Purchase decision process

\section{INTRODUÇÃO}

Desde os tempos antigos, o mercado já fazia parte da vida das pessoas. No passado, quando não existia moeda, o mercado era o local onde as pessoas se encontravam para fazer troca de mercadorias. Para Dias (2003), o mercado se caracteriza pelo conjunto de pessoas e/ou organizações cujas necessidades podem ser satisfeitas por produtos ou serviços e pela necessidade de que estes estejam à venda, para que o adquiram.

Depois da segunda guerra mundial, com o crescimento da população, com o desenvolvimento econômico, com o avanço tecnológico e com a globalização, foram influenciadas as decisões sobre os canais de distribuição ou de marketing. De acordo com a AMA (2008), canais de distribuição constituem um conjunto de empresas e agentes desempenhando as tarefas e fluxos para fazer uma conexão entre produtores e consumidores, ou seja, é um conjunto de esforços que disponibiliza produtos ou serviços aos consumidores finais ou aos clientes industriais.

Para lidar com o mercado, em evolução constante, o canal de distribuição, ou canal de marketing, começou a ganhar importância nas organizações, com o início do desenvolvimento de estratégias de canais de distribuição para colocar os produtos ou serviços à disposição dos consumidores. Esses canais, além de desenvolverem ações que facilitam às empresas alcançar o público final, assumem funções básicas no processo mercadológico, como: fonte de informação sobre mercado, instrumentos e cenários para a promoção de vendas e o merchandising. $O$ uso de intermediários, muitas vezes, aumenta o nível de eficiência contratual (COSTA; EDISON, 1996; KOTLER, 1999; CHURCHILL; PETER, 2000)

Os canais de marketing são divididos em dois níveis (atacado e varejo), que são intermediários, especialistas em disponibilizar produtos ou serviços ao consumidor final. A rigor, atacado é a empresa independente que compra grande quantidade de mercadoria dos fabricantes e passa a ter direito de propriedade. $\mathrm{O}$ atacado faz todo processo de armazenagem e vende para quem revende e para o uso industrial, atendendo, assim, os pedidos dos compradores profissionais, normalmente varejistas, e os usos industriais (COSTA; EDISON, 1996; CHURCHILL; PETER, 2000; DIAS, 1993). Uma das principais funções do atacadista consiste em fornecer cobertura do mercado, pois a finalidade de um produtor ao adicioná-lo na estratégia de distribuição é atingir um maior número de clientes. Dessa forma, o atacadista deve oferecer uma grande cobertura do mercado e ter uma quantidade de venda também consideravelmente grande.

Assim, o varejo é o último elo do canal de distribuição, ou seja, são empresas que vendem produtos, tanto bens duráveis como bens de consumo, ou serviços diretamente ao consumidor final, para uso pessoal e não empresarial, tais como o WalMart, o Magazine Luiza e até mesmo 
a padaria de esquina do bairro. Não importa o tamanho, desde que atue diretamente junto ao consumidor final. Parente (2000) afirma que o varejo consiste nas atividades que envolvem o processo de vendas de produtos e serviços para atender uma necessidade e a satisfação pessoal do consumidor.

De acordo com ABRAS (2010), a importância do varejo no cenário econômico brasileiro vem sendo cada vez mais reconhecida e destacada. Além de ser gerador do maior número de empregos formais no país, o mesmo exibe, especialmente entre os anos de 2000 e 2004 , um crescimento de $11 \%$ em relação a anos anteriores. Desde 2004, o setor de varejo tem tido um comportamento acima do desempenho do PIB brasileiro, sendo responsável por melhorar o resultado geral da economia. Até outubro de 2008, o referido setor teve um crescimento expressivo, consecutivo a cada ano, chegando a $8 \%$ no período de 2006 a 2008. De acordo com IBGE, mesmo com o impacto da crise mundial, o varejo brasileiro cresceu 2,5\% em 2009, representando 5,1\% do PIB nacional, configurando o Brasil como um dos poucos países do mundo a ter esse comportamento positivo, ficando ao lado da Austrália, da Índia e da China (SOUZA, 2009).

Há outros formatos de lojas que são parecidos com o varejo, porém vendem não só para os consumidores finais, mas também para os pequenos varejistas, como bares, restaurantes e padarias, com uma quantidade maior e com um preço menor, são conhecidos como "atacarejo", que é uma mistura entre o atacado e o varejo. Como exemplo, empresas como Makro, Atacadão, Assai, Tenda e Roldão, nas quais a principal diferença é a venda para os pequenos empreendimentos e para os consumidores finais. Então, enquanto o atacado só vende para revenda e para uso industrial, o varejo vende somente para consumidor final e uso pessoal.

Atualmente, o varejo vem se consolidando cada vez mais, com a entrada das grandes redes internacionais no mesmo e com a fusão de empresas, como o grupo Pão de Açúcar e as Casas Bahia. Assim, a consolidação desses varejistas é, de certa forma, um fato que representa, ao mesmo tempo, o poder de barganha sobre os fornecedores e sobre concorrentes. $O$ poder de barganha sobre os fornecedores é ressaltado quando uma grande rede varejista com mais de 100 lojas, resolve efetuar um pedido de compra e impõe os menores preços, o maior prazo e o melhor serviço, deixando, dessa forma, o fornecedor com pouco poder na negociação. Já o poder sobre os concorrentes é demonstrado pela consolidação das redes internacionais, comprando a preços abaixo do mercado, fazendo com que os pequenos e médios varejistas também sofram com essa influência e com que percam, aos poucos, a participação no mercado.

Diante do exposto até aqui, observa-se que a entrada dos atacarejos nesse cenário pode alterar o padrão inicial dos canais de marketing, ocasionando uma potencial ameaça às pequenas e médias empresas distribuidoras. Com base nisso, este estudo aponta como questão problema: Quais são os fatores decisórios que levam os pequenos e médios varejistas a optarem pela compra nos atacarejos em vez de nos distribuidores tradicionais?

O objetivo geral desta pesquisa consiste em avaliar os fatores influenciadores no processo decisório de compra dos clientes de pequenos e médios varejistas, fatores que os levam a migrar suas compras do atacado/distribuidor tradicional para o atacarejo. Os objetivos específicos que irão auxiliar no cumprimento do objetivo principal, a saber: a) identificar a importância dos canais de distribuição, tipos e níveis de canal; b) apresentar os conceitos de tipos de agentes de canais; c) analisar a função do atacado e a do atacarejo; d) demonstrar a evolução do mercado atacadista e do atacarejo no Brasil; e) verificar os impactos da consolidação do varejo para os pequenos varejistas; f) apontar as possíveis estratégias para a distribuidoras tradicionais, principalmente de produtos alimentícios, para obter vantagem competitiva nessa situação. Assim, a pesquisa concentra-se no perfil de varejistas que sejam de pequeno e médio porte e que também tenham sofrido o impacto da entrada dos grandes atacarejos no que se refere aos preços mais baixos, à dificuldade de aumentar 
os clientes e de manter a média de venda por cliente.

Este artigo está estruturado em cinco partes, sendo a primeira delas reservada para a introdução, que aborda o tema e as delimitações, para a definição do problema de pesquisa e para a exposição dos objetivos principal e secundário. Na segunda parte, apresentam-se os referenciais teóricos. Na terceira parte, é apresentada a metodologia. A quarta parte é reservada para a análise e para a interpretação dos dados. Por fim, a última parte trata das considerações finais, das limitações do estudo e das sugestões para futuras pesquisas.

\section{REFERENCIAL TEÓRICO}

\subsection{Canais de marketing}

Esta parte apresenta os conceitos de canais de marketing, sua evolução, importância, seus tipos e níveis de distribuição, fluxos de marketing e agentes relacionados. AMA (2008) define canais de marketing como uma rede ou sistema organizado de agentes e empresas que assumem a responsabilidade de desempenhar as funções e os fluxos necessários a fim de ligar os produtores aos consumidores finais, para execução das tarefas de marketing.

Percebe-se, com o correr dos anos, algumas evoluções nas teorias de canal. Na década de 1970, este é visto apenas como meio ou caminho de levar as mercadorias a partir dos fabricantes, até os consumidores. Já na década de 80 , houve uma pequena mudança no conceito, pois, àquela época, o canal já não era mais visto apenas como um caminho simples de levar produto aos consumidores, uma vez que também lhe foi acrescentada a função de encontrar compradores potenciais para levar os produtos no tempo em que os clientes ou consumidores desejassem, com a condição de fazer a transação da mercadoria. Na década de 1990, o conceito de canal já era visto com maior importância e com maior complexidade. Para Costa ; Edison (1996), canal passa a ser um conjunto de ações e estratégias e de planejamento para tornar os produtos disponíveis aos consumidores. Kotler (1999) reforça, ainda, que o canal envolve o processo de configurar e de operar para atingir o objetivo de distribuição da empresa.

De acordo com essas definições de canal, pode-se entender que, para um fabricante colocar seus produtos ou serviços à disposição dos consumidores, é indispensável ter uma boa estratégia de canal e que, para isso, são necessárias outras empresas especialistas, diretas ou indiretas, sejam lojas de fábrica, distribuidores, atacadistas, varejistas, transportadoras, corretores ou sejam bancos, chamados de intermediários; e cada um tem suas funções específicas na estrutura do canal: alguns compram, armazenam e vendem, fazem toda transação; outros apenas transportam, ou simplesmente passam informações sobre o mercado. Contudo, para decidir qual estrutura a empresa vai utilizar, é necessário entender alguns conceitos sobre tipos de distribuição.

Dias (2003) também afirma que o objetivo da distribuição é fazer com que o produto chegue ao ponto de venda, de uma maneira rápida, segura, pontual e lucrativa para a empresa fabricante ou para o produtor e de maneira acessível, confiável, pontual e segura para o cliente. Conforme Parente (2000), um sistema de distribuição eficaz é um aspecto importante nas estratégias competitivas das organizações, podendo influenciar na sobrevivência destas.

Megido e Szulcsewski (2002) confirmam que vantagem competitiva é estar mais perto do consumidor final e, assim, ter condições de obter informações sobre a satisfação dos seus clientes e informações referentes do mercado, ou seja, quanto mais perto do cliente final, mais rápidas e precisas são as informações.

Para simplificar e explicar a estrutura complexa de canais de marketing, Bowersox e 
Cooper (1992) têm uma teoria de representação tradicional do canal de marketing. A teoria divide a estrutura de canal, basicamente, em quatro níveis como PAVC. Vista numa estrutura de canal, esses são os quatros participantes primários, e cada um exerce funções diferentes. Para os autores Bowersox e Cooper (1992), as estruturas são conforme apresentado na Figura 1:

\section{PRODUTORES $\Rightarrow$ ATACADISTAS $\Rightarrow$ VAREJISTAS $\Rightarrow$ CONSUMIDORES}

Figura 1 - Representação tradicional do canal de marketing - PAVC. Fonte: BOWERSOX; COOPER, 1992.

Como se verificou na Figura 1, há quatro níveis de distribuição para que um produto ou um serviço sejam disponibilizados aos consumidores. Essa é uma estrutura simplificada de um canal de marketing desde produtores até consumidores finais, já que estes também são vistos como agentes. $\mathrm{Na}$ base dessa estrutura, para maximizar os objetivos de distribuição, é necessário apontar e desenvolver a administração do canal de marketing e o fluxo que existe entre esses agentes.

Sob a ótica de um canal, o mesmo pode ser visto como divisão do trabalho numa linha de produção. Para torná-la mais eficaz, é necessário dividir as tarefas entre cada um dos funcionários. No canal, não se produzem produtos, e sim serviços e atividades, sendo as últimas conhecidas como fluxo de marketing (BUCKLIN,1966; COUGLHAN et al., 2002; ROSENBLOOM, 2002).

Alguns fluxos de marketing têm a direção diferente, ou seja, podem ser exercidos de produtores a intermediários, a consumidores ou de consumidores a intermediários e a produtores. Sobre essa lógica, há membros do canal que são especialistas naquilo que fazem: produtores, atacadistas, transportadoras e varejistas, cada um deles tem o objetivo de agregar valor aos produtos e aos serviços que os clientes e consumidores exigem, tais como divisão de grandes quantidades, entrega rápida, conveniência e variedade.

$\mathrm{Na}$ maioria das vezes, o consumidor deseja comprar ou adquirir produtos e serviços em quantidades pequenas, mesmo com preço mais elevado, por diversas razões, tais como a baixa renda ou o fato de ser um consumidor single. Atualmente, com a falta de tempo dos consumidores e as várias opções do mercado, estes procuram por uma entrega mais rápida, com um tempo de espera menor para obter o produto ou o serviço pedido (GIULIANI, 2003b).

Conveniência é a facilidade com que os clientes conseguem encontrar o que desejam, quando e onde não importa. E a procura da variedade refere-se ao sortimento de itens no mesmo local de venda, aumentando, assim, o nível de prestação de serviço ao consumidor final. Para atender a essas exigências, Rosenbloom (2002) define algumas atividades que auxiliam, conhecidas como fluxo de marketing do ponto de vista da estratégia. Os mais importantes fluxos são: fluxo do produto, fluxo de negociação, fluxo de propriedade, fluxo de informação e, por fim, fluxo de promoção.

Rosenbloom (2002), Bruggen, Kacker e Nieuwlaat (2001), complementam que os intermediários são empresas independentes que dão suporte aos produtores e aos fabricantes no desempenho de funções de negociação e de outras tarefas de distribuição. Tais empresas operam em dois níveis: atacado e varejo. De fato, são muitos os tipos de intermediários envolvidos nessa estrutura, porém, basicamente, são classificados em um dos referidos níveis. Como citado anteriormente, para minimizar os riscos da distribuição, é necessário ter um bom planejamento, decidir qual intermediário vai fazer parte do canal e qual o nível de distribuição.

De acordo com Donnelly (1976), alguns intermediários assumem riscos ou propriedades. Muitas vezes, estes exercem várias funções (fluxos) de marketing, outras vezes, trabalham com a função de facilitadores, criando condições ao produtor para disponibilizar seus produtos aos consumidores ou ao financiamento do canal. Em contrapartida, é importante definir e identificar 
cada função que deve ser exercida pelos intermediários nos canais de distribuição (DONNELLY, 1976; ETGAR; ZUSMAN, 1982).

As principais vantagens de se utilizar intermediários na distribuição, para Couglhan et al. (2002), são: motivação; especialização; sobrevivência do mais apto economicamente; economias de escala; maior cobertura de mercado; independência de qualquer produtor individual. A seguir, explicita-se cada uma dessas vantagens.

Os grandes distribuidores e atacadistas estão cada vez mais aptos e preparados para fornecer informações precisas, maior cobertura do mercado e para reduzir custos de estocagem e armazenagem. Os produtores estão optando pela distribuição por meio desses intermediários para obterem maior eficiência na distribuição e maior prestação de serviço para os consumidores (BUCKLIN, 1996).

Para Rosenbloom (2002), a utilização ou não dos intermediários se divide em dois conceitos básicos, o primeiro é a especialização e a divisão do trabalho e o segundo é a eficiência contratual. A especialização, numa linha de produção, aumenta a eficiência de produção, pois cada operário é especialista naquilo que faz, e o mesmo princípio se aplica aos canais de distribuição. Assim, cada intermediário é especialista nas suas atividades, sejam estas fabricação, distribuição, vendas ou sejam entregas. O resultado dessa divisão de tarefas é o aumento da eficiência e a redução de custos de distribuição. A diferença entre produção e distribuição é a organização das tarefas. Em uma linha de produção, as tarefas são organizadas pelo fabricante, e, em um canal de distribuição, as atividades e as tarefas são organizadas interorganizacionalmente. O gestor do canal, muitas vezes, não tem controle total das organizações envolvidas, mas pode determinar o nível e a extensão do canal. Outro conceito que influencia essa decisão de uso é que o mesmo aumenta a eficiência contratual (COUGLHAN et al., 2002; CHURCHILL.; PETER, 2000; ROSENBLOOM, 2002). De acordo com Bruggen, Kacker, Nieuwlaat (2001) e Rosenbloom (2002), a eficiência contratual é o nível de esforço que os produtores fazem para disponibilizar seus produtos e serviços para o consumidor final.

A principal razão para o uso dos intermediários é reduzir os esforços do canal de marketing, eliminando a necessidade de manter contato direto com todos os compradores e separando, assim, o esforço de distribuição da produção (DONNELLY, 1976; ROSENBLOOM, 2002). Porém, isso não significa que todos os produtores devam utilizar intermediários. Antes de tomar qualquer decisão sobre o uso ou não dos intermediários para distribuição, é necessário também fazer algumas perguntas, tais como: temos capacidade para vender diretamente (estrutura para armazenagem, própria força de venda, criação de propaganda, profissionais em disposição de pré e pós-venda, recursos para financiamento do cliente e para entrega dos produtos)?. Há algum membro do canal independente que pode desempenhar tal fluxo com um custo baixo? Na literatura de marketing, os autores, muitas vezes, não definem claramente o conceito da estrutura do canal, a maioria deles explica a estrutura do canal por meio da extensão e do nível de intermediários participantes (ROSENBLOOM, 2002). O canal de marketing, ou canal de distribuição, é identificado com os números de participantes, intermediários ou agentes, sendo que, em cada nível, os intermediários e os agentes são diferentes.

Verifica-se que, em todos os níveis de canais, há fabricantes, produtores e consumidores. Agentes produtores, ou fabricantes, são aqueles que criam ou transformam matérias-primas em bens de consumo ou em bens duráveis. Além disso, eles também criam marcas e agregam valores. Assim, dentro de uma estrutura de canal, o papel de um produtor torna-se extremamente importante. Onde há ser humano, há consumo. Por isso é que todos os níveis de canal chegam aos consumidores, sejam eles consumidores de bens de consumo ou de bens duráveis, é neles que todo foco se concentra. 
Em extensão ao canal, existem basicamente dois tipos de distribuição: distribuição direta e distribuição indireta (COUGLHAN et al., 2002; CHURCHILL; PETER, 2000; ROSENBLOOM, 2002; KOTLER, 1999). Distribuição direta é quando o fabricante decide colocar os produtos no mercado, vendendo diretamente aos consumidores, com seu próprio ponto de venda, e eliminando os intermediários, o que diminui o custo do produto, conforme acontece nas lojas de fabricas (COSTA; TALARICO, 1996; PARK; KEH, 2003). Segundo Giuliani (2003a), distribuição indireta é o sistema de distribuição e venda para cuja realização o produtor utiliza grupo(s) de empresas ou organizações independentes, não vinculadas a ele, as quais assumem o processo de colocar o produto disponível para uso e consumo do público final.

Não existe um formato de distribuição melhor, tudo depende do objetivo de distribuição da empresa. Quando a informação, a customização e o conhecimento do produto ou do serviço forem de alto nível, a distribuição direta será mais adequada. E quando a exigência de nível de serviço for maior, o canal indireto será mais adequado (COUGLHAN et al., 2002). Costa e Talarico (1996) confirmam a ideia de que a distribuição indireta exige menores investimentos do que a direta, isto é, os custos são mais baixos, e o retorno obtido muito maior.

Há, porém, outra forma, que utiliza as duas distribuições ao mesmo tempo, conhecida como distribuição Dual, normalmente utilizada com a finalidade de atingir maior cobertura de mercado, de reduzir custos de distribuição e de criar bloqueios para novos entrantes (KOTLER, 1999; COUGHLAN et al., 2002). Como exemplo pode-se citar a IBM e as editoras de livros, que adicionaram a venda e a distribuição pela internet, para atingir maior cobertura de mercado, relacionando-se com o intensidade do canal.

A intensidade do canal refere-se ao número de intermediários, em cada um de seus níveis, utilizados pelo produtor para disponibilizar os produtos e os serviços ao consumidor final (COUGHLAN et al., 2002; FRAZIER; LASSAR, 1996; PARK; KEH, 2003; ROSENBLOOM, 2002). Dessa forma, a intensidade do canal é dividida em três categorias: distribuição intensiva, distribuição seletiva e distribuição exclusiva.

A distribuição seletiva utiliza um número reduzido de intermediários. Todos são cuidadosamente selecionados para exercer alguns fluxos de marketing. Já a distribuição intensiva, conhecida como saturada, normalmente é utilizada para atingir um maior número possível de clientes e uma maior cobertura do mercado possível, nessa categoria, enquadram-se os produtos de bens de conveniência tais como, papel higiênico, cremes dentais, saco de lixo, entre outros. Por fim, a distribuição exclusiva é uma forma padrão e altamente seletiva de distribuição, ou seja, usa apenas um número limitado de intermediários em cada nível de canal e é normalmente empregada para se ter maior controle da qualidade do serviço e do produto (CONSOLI, 2005; ROSENBLOOM, 2002).

Para decidir qual a intensidade do canal a utilizar, os gestores da área devem definir antes qual o objetivo de distribuição da empresa, e depois identificar quais os agentes existentes e disponíveis no canal para exercerem os fluxos com melhor custo e benefício (MALLEN, 1996). Para isso, precisase observar o número de intermediários a serem adicionados nas relações. Os intermediários são agentes entre o produtor/fabricante e o consumidor final/cliente profissional, sendo que aqueles utilizam diversos tipos de fluxo do canal para disponibilizar os produtos ou serviços aos clientes, sendo os principais: Atacado, Varejo e Agentes facilitadores.

\subsubsection{Atacado}

Desde a década de 1980, o atacado vem evoluindo tanto nos conceitos quanto nas funções. Intermediários de atacado são as empresas engajadas nas vendas de bens para revenda ou para uso industrial. Entre as funções dos atacadistas num canal de distribuição destacam-se: fornecer cobertura ao mercado; fazer contato de vendas; manter estoques; fracionar quantidade dos produtos; processar pedidos; distribuir produtos; reunir informações do mercado; oferecer suporte ao cliente; e dar crédito e auxílios financeiros (STERN et al., 1996; ROSENBLOOM, 2002; BERMAN, 1996). 
No Brasil, o setor atacadista teve um crescimento real de $4 \%$ em 2010, comparado com o de 2008. Segundo a ABAD (2010), o setor é responsável pelo abastecimento de $53 \%$ do canal alimentar do país. De acordo com o Ranking da Abad 2009, realizado com 364 empresas, o setor atacadista de distribuição encerrou o ano de 2009 com um faturamento de $\mathrm{R} \$ 120,8$ bilhões, o que corresponde a um crescimento de 8,5\% em relação a 2007. Na modalidade de autosserviço, quem lidera o ranking de 2009 dos atacadistas é o Makro, com um faturamento de R\$ 5.114.340.533; em segundo lugar, vem o Assaí, com um faturamento de $\mathrm{R} \$ 2.196 .500 .000 ; \mathrm{e}$, em terceiro lugar vem o Tenda, atacado com faturamento de $\mathrm{R} \$$ 1.309.700.000. Para os pequenos e médios atacadistas, isso se torna uma grande ameaça para 0 próprio crescimento.

Dessa forma, os atacadistas de pequeno e médio porte, enfrentam várias ameaças no mercado, como: a dificuldade de sobrevivência dos pequenos e médios varejos, a ausência de fidelidade, a concorrência predatória de preço dentro do setor, o incentivo dos fabricantes a novos canais que eliminam o atacado, e as grandes redes realizando as funções do atacado, como o atacarejo e a internet (NEVES, 1999). Segundo esse autor, só sobrevivem no cenário atual os atacadistas que: a) não focam apenas no preço, mas também no serviço e nas necessidades dos clientes; b) são especializados; c) modernizam os sistemas de controle; d) conseguem lealdade do varejo com relacionamento; e) são operadores logísticos; f) têm bom relacionamento com os fabricantes.

Observa-se que os fatores mais valorizados pelos médios e pequenos varejistas são: preço, prazo de pagamento, prazo de entrega, entrega feita de acordo com o pedido, atendimento apropriado das reclamações, sortimento/variedade dos produtos, frequência de entrega, frequência de visita do vendedor, relacionamento, venda com quantidades fracionadas, novidades com relação aos produtos e suporte prestado.

Para os atacadistas, os clientes são, em sua maioria, varejistas de médio e pequeno porte, pois as grandes redes de varejo, normalmente, eliminam os atacados e negociam diretamente com os produtores, diminuindo, assim, o custo da compra, pois eles têm estrutura e poder para comprar grande quantidade de produtos. Assim, para os atacadistas, é necessário entender quem são seus clientes.

\subsubsection{Atacarejo}

O Atacarejo é um novo formato de distribuição no mercado, que pode ser compreendido como uma loja que mistura as atividades de atacado e varejo. Como exemplo, pode-se citar o Makro. Este é um dos melhores modelos para representar o atacarejo, pois sua principal característica é a venda para os pequenos empreendedores, muitas vezes, informais. Para aqueles consumidores que procuram o melhor preço e não,o conforto, a empresa oferece preços competitivos, porém ainda não oferece serviços de entrega, ou seja, o cliente que deseja comprar deve ir à loja e levar os produtos adquiridos para sua casa ou seu comércio. Outro inconveniente é que, geralmente, dentro da loja, é difícil achar um atendente para solucionar as dúvidas dos clientes. A maioria das lojas do Makro apresentam o mesmo layout, com prateleiras extremamente altas. As mercadorias que são fracionadas ficam no meio das prateleiras; para baixo e para cima das gôndolas, ficam os estoques, as caixas e as caixas de mercadorias; os refrigerantes são comercializados, muitas vezes, em fardos fechados, com preços baixos para atrair os clientes.

De acordo com Carvalho (2009), os grandes atacarejos no mercado de hoje são: Atacadão, que pertence ao grupo francês Carrefour, e tem um faturamento anual de 6,5 bilhões; o Makro, com seu faturamento de 4,9 bilhões ao ano; o Assai, do grupo Pão de Açúcar, com um faturamento anual de 1,5 bilhão, o Maxxi pertencente à rede Walmart, com faturamento de 1,3 bilhões por ano e, por fim, o Tenda, uma empresa familiar, com 1,2 bilhão de faturamento anual. 
Para alcançar o objetivo principal, até agora, foram levantados os conceitos que envolvem canais de marketing, dando-se enfoque ao atacado e ao atacarejo, e, para identificar quais são os fatores que influenciam o cliente a escolher entre atacado e atacarejo, é necessário estudar o comportamento do cliente, o que será abordado no próximo capítulo.

\subsection{Comportamento do consumidor}

Este capítulo aborda os conceitos sobre comportamento do consumidor, clientes profissionais, processo de compra e, por fim, as variáveis de compra. O comportamento do cliente é também conhecido como comportamento do consumidor, porém há uma diferença entre os dois, pois os clientes não compram para consumo próprio e sim para uso industrial ou para revenda, como no caso dos varejistas. Este estudo se concentra no comportamento do cliente, empresas que compram, não com a finalidade de consumo, e sim de revenda.

Antes de se aprofundar no assunto, é necessário que se entenda alguns conceitos do comportamento do cliente. Uma das mais tradicionais definições de comportamento de consumidor é de Howard e Sheth (1969), que afirmam que o comportamento do consumidor é a decisão sobre a escolha das marcas, repetidamente, a qual é definida pelo conjunto de motivos e alternativas para decisão. De acordo com Minor e Mowen (2003), o comportamento do consumidor pode ser compreendido como um estudo dos indivíduos compradores e dos processos de troca envolvidos no consumo e na aquisição do produto e do serviço.

Para Solomon (1998), o comportamento do consumidor é um processo envolvendo indivíduos ou grupos que compram, selecionam, usam ou consomem produtos e serviços, ou seja, são atividades físicas (compra), mentais (decisão), em busca da obtenção dos produtos e serviços, bem como pagando por estes para satisfazer suas necessidades e seus desejos (ENGEL; 2000; HAWKINS et al., 2001; SHETH; MITTAL; NEWMAN, 2001).

Segundo Gade (1980), o cliente e consumidor é o destinatário dos produtos e serviços que os produtores e agricultores produzem e que depois os atacadistas e varejistas distribuem. Dessa forma, compreender o comportamento deles é de extrema importância para entender qual é a relação entre o produto e o cliente. Uma das mais recente definições sobre comportamento do cliente é de Blackwell et al. (2005). Para eles, o comportamento é mais amplo do que para alguns autores anteriores que caracterizaram este como "as atividades de compra, uso e obtenção de produtos e serviços". Assim, Blackwell et al. (idem) afirmam que o comportamento é um campo de estudo que foca nas atividades do consumidor.

A decisão de compra dos consumidores é influenciada por vários fatores, que são, praticamente, divididos em três categorias: diferenças individuais, diferenças ambientais e processo psicológico (BLACKWELL; MINARD; ENGEL, 2005). As diferenças individuais e ambientais que influenciam a decisão de compra dos consumidores envolvem demografia, valores, psicografia, recursos, motivação, conhecimento, classe social, família, amigos e cultura. O fator processo psicológico, por sua vez, envolve, basicamente, a aprendizagem dos indivíduos.

Kotler (1999) afirma que existem dois fatores que influenciam a decisão de compra dos consumidores. O primeiro fator é a influência de outras pessoas, como familiares ou amigos que contribuem para uma mudança na decisão de compra; e o segundo fator referese aos imprevistos, tais como desemprego, alta de taxas de juros ou até mesmo restrição de renda, impedindo ou adiando o ato de comprar.

Porém a decisão de compra dos consumidores é diferente da dos compradores profissionais, daqueles que compram para revender, os quais, neste estudo, são considerados 
os varejistas de alimentos. Para esses varejistas, a decisão de compra está diretamente ligada às necessidades dos consumidores finais (SOLOMON, 2002). Segundo Sheth, Mittal e Newman (2008), a necessidade e a motivação dos consumidores são diferentes das dos clientes industriais. Para os consumidores, as necessidades estão voltadas à parte fisiológica (fome, sede), à segurança e ao reconhecimento próprio. Para os clientes, as necessidades estão voltadas à sobrevivência da empresa, às competências essenciais e ao reconhecimento do mercado.

A principal diferença entre a compra para consumo e a compra comercial é a quantidade. Para consumo comercial, a quantidade é muito maior do que para consumo pessoal. Outra diferença é o sortimento: para consumo pessoal, muitas vezes, compra-se com enorme variedade; já para o comercial, nem sempre a compra, com o mesmo fornecedor ou produtor, é de grande variedade.

Os consumidores compram para atingir seus desejos e desfrutar os benefícios dos produtos ou serviços, então, podem comprar por impulso, por influência de terceiros ou de propagandas. Dessa forma, os cliente ou consumidores são motivados e influenciados por alguma razão, para a decisão de compra (SHETH; MITTAL; NEWMAN, 2001).

Segundo Kotler (1998), até o momento da compra, há um processo decisório, que passa pelo cliente e pelo consumidor, de reconhecimento da necessidade ou do desejo que impulsiona da compra até o comportamento de pós-compra, o qual gera satisfação ou frustração.

Assim, observa-se que são vários os estímulos que impulsionam os clientes a tomarem uma decisão de compra. Influências tais como fatores culturais, sociais, individuais e psicológicos, são consideradas como internas de cada um; as influências externas vêm do macro ambiente, como os fatores econômico, tecnológico, político e cultural, além dos estímulos do composto de marketing. Depois, esses estímulos fazem com que o cliente comece um processo de decisão de compra até chegar à escolha dos produtos ou serviços a serem adquiridos.

Após todos esses fatores de influência e motivação, o cliente, ou consumidor, entra em processo de decisão pela escolha de qual produto comprar, de qual marca adquirir, de qual vendedor, em qual época e de qual a quantidade que deseja comprar. O comportamento do consumidor muda pelas experiências anteriores de compra e consumo, por meio do processamento de informações (ROBERTSON et al, 1984).

Para entender o processo de decisão e de compra, é necessário entender quem participa do processo e quais os papéis desempenhados na compra. A fim de entender como o cliente toma a decisão de compra, é fundamental apreender o processo de compra e os fatores influenciadores que podem mantê-lo fiel (PRADO, 2008). Como citado anteriormente, há diferentes papéis envolvidos no processo de compra, estes são classificados praticamente em três: Comprador, Usuário e Pagante (GADE, 1980; KOTLER, 1998; SHETH; MITTAL; NEWMAN, 2001). Comprador é aquele que participa da obtenção do produto no mercado; Usuário é aquele que realmente consome o produto e; Pagante é o indivíduo que faz a transação financeira do processo de compra.

Assim, muitas vezes, o indivíduo pode exercer os três papeis de consumidor, ou apenas um, como por exemplo: um pai de família que paga as contas, mas nem sempre é o comprador, aleatoriamente a mulher que vai ao supermercado comprar comidas; esse pai de também nem sempre é usuário, como no caso do laptop do filho, o pai é o pagante, e o filho é o verdadeiro usuário; ou então, quando o pai decide tomar um café no shopping, ele pode escolher onde comprar, consumir e pagar e, então, exerce os três papéis de cliente.

Numa empresa grande, normalmente os três papeis são bem distintos, cada um é de setor diferente, como setor de compra, de finanças e de fabricação do produto. Numa empresa de médio porte, muitas vezes, o proprietário exerce os três papeis como, por exemplo, em uma oficina mecânica, o mecânico faz o pedido da peça compra, ele mesmo monta e depois paga. Dessa forma, a diferença dos papeis e a identificação dos mesmos são de extrema importância para os 
profissionais de marketing, pois cada um tem a sua motivação, fatores diferentes que influenciam na decisão de compra (BLACKEWELL; MINIARD; ENGEL, 2005; SHETH; MITTAL; NEWMAN, 2001).

O comportamento de compra passa por estágios diferentes, o que alguns autores denominam de Modelo do Processo de Decisão de Compra, coforme organização a seguir : a) Reconhecimento da necessidade; b) Busca de informações; c) Avaliação de Alternativas pré-compra; d) Compra; e) Consumo; f) Avaliação pós-consumo; g) Descarte (BLACKEWELL; MINIARD; ENGEL, 2005)

A visão de Blackwell, Minard e Engel (2005) é voltada mais para o consumidor final, cuja compra é feita com finalidade de consumo e não para a revenda. Assim, quando se trata de clientes que compram para revenda, o processo de compra é visto de outra forma. Para esses autores, as variáveis apontadas como fatores na decisão de compra dos consumidores podem ser divididas em três categorias: diferenças individuais, influências ambientais e processos psicológicos.

Depois de compreender as variáveis de decisão de compra do consumidor, é importante, também, entender as variáveis que influenciam a decisão de compra do cliente (ALMEIDA, 1996). $O$ foco deste estudo é o comportamento do cliente sob a ótica dos atacadistas, que normalmente são varejistas ou indústrias.

Os varejistas têm que estar atentos às necessidades dos consumidores, saber qual produto devem comprar, em que quantidade e em que sortimento. Isso depende da procura pelos produtos, da pesquisa de mercado e, junto aos fornecedores, dos preços acessíveis aos consumidores, da negociação e do melhor prazo de pagamento, de acordo com a situação financeira da empresa.

Os atacadistas devem estar atentos às necessidades dos clientes, a qual produto deve comprar, à quantidade a ser fracionada e à variedade que deve ter. Isso tudo depende da procura pelos produtos, de pesquisa de mercado e, junto aos fornecedores, de preços acessíveis aos consumidores, da negociação da maior parcela e do melhor prazo de pagamento, de acordo com a situação financeira da empresa.

Segundo Arnold (1999), as funções de compra são o conhecimento do produto certo, a hora certa, a entrega certa (tempo e lugar), a fonte correta e o preço adequado. Por outro lado, os atacadistas têm o grande desafio de vender para outras organizações, os varejistas, e é importante ressaltar que, para vencer esse desafio, é necessário entenderem quais os aspectos mais relevantes na hora da decisão de compra, formando, assim, estratégias que possam contribuir para a obtenção de vantagens competitivas, o que pode ser considerado como um ponto positivo para a organização.

\section{METODOLOGIA DE PESQUISA}

Nesta parte, apresenta-se a metodologia a ser empregada no presente estudo, destacandose o método, as técnicas e os tipos de pesquisa, bem como os instrumentos de pesquisa e de tratamento dos dados, com o objetivo de verificar a decisão de compra dos clientes.

O principal objetivo desta pesquisa consiste em avaliar os fatores influenciadores no processo decisório de compra dos pequenos e médios varejistas. A fim de atingi-lo, é necessário ter-se alguns pressupostos. $O$ pressuposto inicial é que, com o mercado do setor de atacado mais competitivo, a escolha entre atacadistas tradicionais ou atacarejos são bem distintas. Dessa forma, observa-se que: para os clientes como bares, restaurantes e padarias, a escolha pelo atacarejo pode ter, como principais fatores influenciadores, melhor preço, fracionamento e, ao mesmo tempo, a possibilidade de ter menor estoque, diminuindo, assim, seus custos de armazenagem (Pressuposto 1); e, para os clientes que fazem a opção por atacadistas tradicionais, os principais fatores influenciadores podem ser maior confiabilidade, melhor relacionamento, maior sortimento (marcas e linhas) de mercadorias e conveniência (Pressuposto 2). 
Para atender aos objetivos propostos, o estudo se caracteriza por ser uma pesquisa exploratória com a utilização de métodos quantitativos, para os quais os dados foram levantados junto aos clientes da Distribuidora J.P. de produtos alimentícios, localizada na cidade de Piracicaba/ SP. Este artigo caracteriza-se por ser uma pesquisa exploratória que, segundo Malhotra (2001), tem por finalidade, entre outras, a busca de opiniões e critérios para desenvolver uma abordagem que atenda ao problema exposto e que estabeleça prioridades para pesquisas futuras.

Segundo Aaker, Kumar e Day (2001), quando se planeja uma pesquisa, existe uma ampla variedade de métodos a serem considerados, seja de forma individual ou seja de forma combinada. Isso significa que existem métodos diferentes de se coletar dados, sendo que, no presente trabalho, utilizar-se-á o estudo de caso ilustrativo, selecionando-se a Distribuidora J.P. de produtos alimentícios. Serão utilizados questionários para coleta de informações. Segundo os referidos autores, um questionário bem elaborado atinge os objetivos da pesquisa, os quais precisam ser elaboradas sob medida para as especificações de um dado propósito de pesquisa. Portanto, é preciso ter bastante critério ao se formularem as perguntas.

Os questionários podem ser feitos com perguntas abertas e fechadas. Segundo Aaker; Kumar; Day (2001), as perguntas abertas podem ser utilizadas em conjunto com as fechadas para se obterem informações adicionais. Com base nessa premissa, os autores adotaram esse método de questionário. Assim, para alcançar os objetivos, a pesquisa foi dividida em três fases, conforme descrito a seguir.

A primeira fase, caracterizada como exploratória, é aquela na qual se buscou, nos dados secundários, como livros, artigos, teses e revistas nacionais e internacionais, conteúdo para a construção do referencial teórico. A segunda fase caracteriza-se como pesquisa qualitativa descritiva que, de acordo com Malhotra (2001), é como uma pesquisa não estruturada, baseada em pequenas amostras para compreensão do problema. Nessa fase, utilizaram-se entrevistas em profundidade junto aos clientes, tendo sido selecionados os pequenos e médios varejistas de produtos alimentícios, para que se coletassem informações sobre decisões de compra. Selecionaram-se oito clientes, aleatoriamente, sendo: três padarias, duas mercearias e três bares, a partir dos quais se procurou identificar o que os varejistas levam em conta no processo decisório de compras. Essa fase, considerada como um pré-teste de pesquisa, procurou corrigir os problemas de precisão e clareza das perguntas, visando ajustar a quantidade de perguntas para melhorar a qualidade do questionário antes de ser estendido à amostra e à verificação da sequência das questões, se estas estavam corretas e, principalmente, se as perguntas permitiram atingir os objetivos do estudo. A ferramenta aplicada foi a da entrevista semiestruturada. As perguntas foram aplicadas no pré-teste com o objetivo de identificar quais são os canais indiretos que os varejistas preferem e quais são os principais fatores que influenciam no processo decisório de compra, baseando-se nos modelos de variáveis da decisão de compra de Assael (1992); Chaves (2002) e Almeida (1996), permitindo, assim, entender quais são as razões que levam os clientes a agirem dessa maneira. $A$ análise das entrevistas permitiu verificar 0 mix de produtos adquiridos e os critérios de compra e a seleção de tipos de canais indiretos. A terceira fase consistiu na aplicação de um questionário no qual foram adotadas questões semiestruturadas oriundas do pré-teste realizado junto aos clientes da Distribuidora J.P. de produtos alimentícios.

Foi aplicado o questionário a um total de 93 clientes, os quais representam o total dos clientes ativos em Piracicaba, que efetuam compra semanalmente, sendo que apenas um dos 93 clientes não respondeu ao questionário. Também foram selecionados outros 10 clientes ativos entre aqueles localizados nas intermediações da região em que a empresa atua. $O$ questionário aplicado contém 6 questões, sendo uma em escala de Likert de 1 a 5, e as demais questões fechadas. Essa fase teve como finalidade qualificar e generalizar as informações referentes à etapa anterior, que são as variáveis de decisão de compra dos clientes entrevistados; o valor gasto na compra de mercadorias, 
com os atacadistas e com o atacarejo; e a frequência de compra.

$O$ processo de tratamento dos dados e a interpretação dos resultados da pesquisa foram provenientes dos questionários aplicados aos clientes. Os dados obtidos receberam uma tabulação de forma quantitativa, com apresentações por meio de gráficos e de tabelas, e foram analisados com base na média, mediana e desvio padrão, para auxiliar na avaliação dos pressupostos e objetivos apontados pela pesquisa.

Para análise dos resultados, inicialmente foram feitas as estatísticas descritivas das questões qualitativas. A questão em escala de Likert, referente aos fatores considerados importantes pelo cliente ao realizar suas compras, também foi analisada qualitativamente, considerando as notas de 1 a 5 como: 1 = nada importante; 2 = pouco importante; 3 = razoavelmente importante; 4 = importante; e 5 = extremamente importante. Para essas mesmas questões, também foi feita a análise quantitativa através dos desvios das médias obtidas em cada opção em relação à média geral da questão.

\section{ANÁLISE E INTERPRETAÇÃO DOS DADOS}

Neste capítulo, apresentam-se os resultados das pesquisas relativas aos fatores que levam os clientes da Distribuidora JP a migrarem suas compras do atacado-distribuidor tradicional para o atacarejo. No que se refere aos valores de compras mensais, verifica-se concentração $(52,17 \%)$ nos clientes que compram entre $\mathrm{R} \$ 5.000,00$ e $\mathrm{R} \$ 10.000,00$. A distribuição dos clientes segundo a responsabilidade pela compra na empresa concentra-se no proprietário $(92,39 \%)$, característica de empresas de pequeno porte, nas quais o proprietário desempenha diversas funções.

Foram feitas quatro classificações para melhor entendimento. Os clientes que realizam suas compras acima de $60 \%$ no atacado ou no atacarejo foram classificados como clientes de "maior parte compra no atacado" ou "maior parte compra no atacarejo". Do total, 43,48\% dos clientes realizam suas compras somente no atacado, e, ainda, 22,83\% realizam a maior parte da compra no atacado. Os clientes que realizam maior parte de compra no atacarejo representam $32,61 \%$ do total.

Ao se analisar a distribuição de frequência dos clientes entrevistados, segundo perfil do cliente em relação ao percentual de compra realizada no atacado ou no atacarejo e respectivo ramo de atividade, observa-se que os dados mostram a preferência de compra de cada segmento, ressaltando que os clientes que mais migraram suas compras para o atacarejo são os bares e as padarias, que representam $9,78 \%$ das que realizam maior parte de compra no atacarejo. Em contrapartida, $16,30 \%$ dos bares e padarias ainda são fieis à distribuidora J.P. Os minimercados e as mercearias também estão migrando suas compras do atacado para o atacarejo, ambos representam $4,35 \%$, e realizam a maior parte da compra no atacarejo.

Em relação ao valor gasto e à preferência de compra, pode-se perceber que, dos clientes que compram somente no atacado, $16,30 \%$ gastam de $R \$ 1.000,00$ a $R \$ 5.000,00$ dos orçamentos em produtos alimentícios por mês; $17,39 \%$ gastam de $R \$ 5.000,00$ a $R \$ 10.000,00$ por mês, e, 9,78\% gastam de $\mathrm{R} \$ 10.000,00$ a $\mathrm{R} \$ 50.000,00$ por mês no atacado. Porém, $11,96 \%$ dos clientes que compram a maior parte no atacarejo gasta de $R \$ 1.000,00$ a $R \$ 5.000,00$, e $19,57 \%$ dos clientes gastam de $\mathrm{R} \$ 5.000,00$ a $\mathrm{R} \$ 10.000,00$, apenas $1,09 \%$ dos clientes compra de $\mathrm{R} \$ 10.000,00$ a $\mathrm{R} \$ 50.000,00$ por mês.

Quanto aos fatores considerados importantes pelos clientes, observa-se que o preço e o prazo de pagamento são considerados como menos importantes. Nota-se que os clientes classificam a importância da conveniência na decisão de compra. A pesquisa indicou que $60,87 \%$ dos clientes consideram a conveniência extremamente importante na hora da compra; $9,78 \%$ classificam como importante; $8,70 \%$ como razoavelmente importante; e 19,57\% pouco importante. A importância 
da confiança na decisão de compra aponta que $56,52 \%$ dos clientes categorizam a confiança como extremamente importante, ou seja, mais que a metade, e $20,65 \%$ como importante; $13,04 \%$ razoavelmente importante; e, apenas $8,7 \%$ acredita que a confiança é pouco importante.

Sobre a classificação dos clientes diante da importância da variedade na decisão de compra, $27,17 \%$ consideram a variedade dos produtos oferecidos na hora de compra como extremamente importante; $31,52 \%$ consideram importante; $21,74 \%$ consideram razoavelmente importante; $18,48 \%$ consideram pouco importante; e,apenas 1,09\% consideram nada importante o fator variedade na hora da compra.

É possível verificar a importância do preço na decisão de compra. Destaca-se que 30,43\% dos clientes consideram o preço extremamente importante; $13,04 \%$ julgam importante; $38,04 \%$ consideram razoavelmente importante o fator preço na hora de compra; $17,39 \%$ consideram pouco importante; e apenas 1 entrevistado (é mais adequado que continue utilizando a porcentagem) considera nada importante.

A importância da entrega na decisão de compra demonstra que $63,04 \%$ dos clientes classificam esse fator extremamente importante; 3,26\% importante; 6,52\% acreditam ser razoavelmente importante; e os números que consideram pouco importante e nada importante são $14,13 \%$ e 13,04\%. Nota-se que as porcentagens apresentadas são bastante opostas.

A classificação com relação à importância do prazo de pagamento para os clientes destaca que $8,7 \%$ apontam como extremamente importante; $26,09 \%$ categorizam como importante; $17,39 \%$ veem como razoavelmente importante; $31,52 \%$ pouco importante; e, $16,30 \%$ consideram nada importante, ou seja, $47,82 \%$ dos clientes não acreditam que o prazo de pagamento seja um fator relevante para as suas decisões de compra.

A importância do fracionamento na decisão de compra evidencia que $60,86 \%$ não consideram o fator fracionamento como importante para as suas decisões de compra. Do total, $30,43 \%$ acham pouco importante; e $25 \%$ dos clientes consideram importante. Apenas $5,43 \%$ consideram extremamente importante o fracionamento.

A Figura 2 aponta o desvio e a média em todos os fatores questionados. Os clientes atribuíram 3,5 em média, para a importância em todos os fatores questionados, e os fatores que estão abaixo dessa média, tais como prazo de pagamento e fracionamento, são considerados menos importantes em função dos demais. Os fatores considerados mais importantes são: confiança, seguido de conveniência, entrega, variedade e preço.

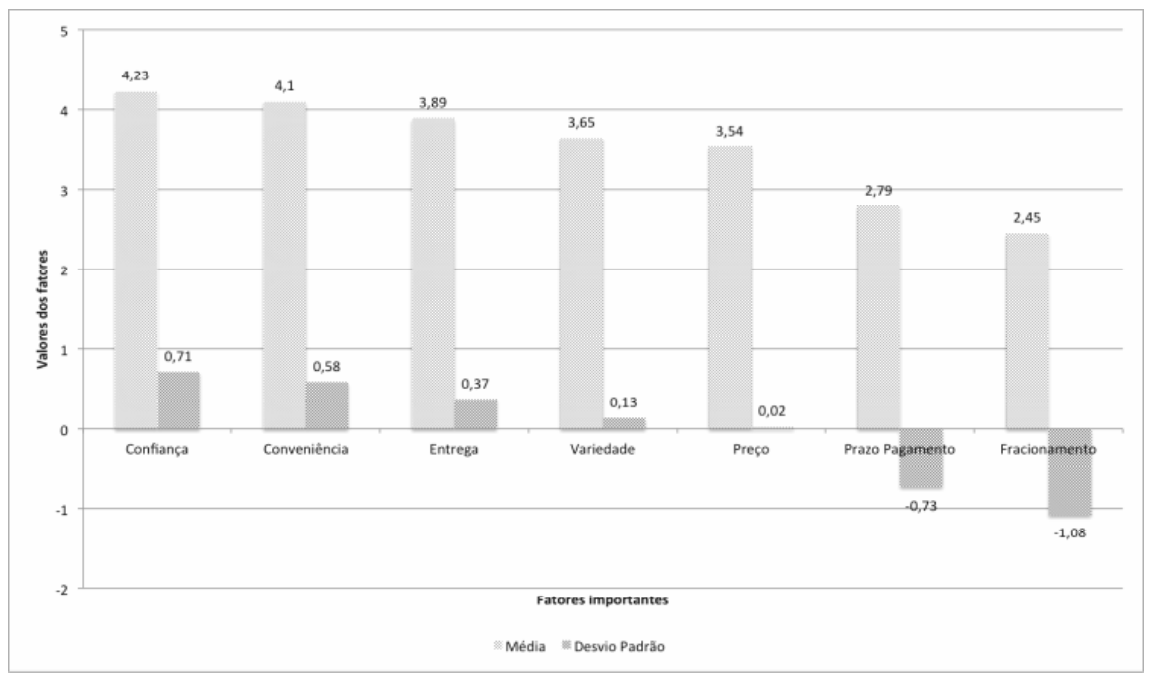

Figura 2. Fatores considerados importantes na hora da compra. 
No cruzamento entre o perfil do cliente e a classificação de importância para o fator de conveniência, observa-se que $60,87 \%$ dos clientes entrevistados classificam a conveniência como extremamente importante. Dentre esses, $43,48 \%$ compram somente no atacado e $15,22 \%$ compram a maior parte no atacado. Dos entrevistados, $19,57 \%$ classificam como pouco importante o fator conveniência, estes são os que compram a maior parte no atacarejo. Ou seja, os que realizam suas compras no atacarejo não dão muita importância para a conveniência.

$\mathrm{Na}$ interação entre o perfil dos clientes e a classificação de importância para o fator de confiança, observa-se que a maioria dos clientes classificam a confiança como fator importante na decisão de compra, pois $56,52 \%$ deles classificam como de extrema importância o fator de confiança. Dentre esses clientes, $42,39 \%$ realizam suas compras somente no atacado e $14,13 \%$ compram a maior parte no atacado; $20,65 \%$ classificam o fator confiança como importante na decisão de compra; e apenas $8,70 \%$ e 1,09\% o classificam pouco ou nada importante.

Ao cruzar as informações do perfil de cliente e a classificação de importância para o fator variedade na decisão de compra, sendo que $27,17 \%$ dos entrevistados o classificam como extremamente importante e, dentro desses números, $22,83 \%$ compram somente no atacado e $4,35 \%$ fazem a maior parte das suas compras no atacado; e 31,52\% o classificam como importante, sendo que $15,22 \%$ compram somente no atacado e $14,13 \%$ fazem a maior parte da compra no atacado; $18,48 \%$ classificam como pouco importante o fator variedade e também fazem a maior parte da compra no atacarejo.

Ao se fazer a análise entre o perfil do cliente e a classificação de importância do fator preço, destaca-se que $30,43 \%$ dos clientes o classificam como extremamente importante, e todos fazem a maior parte da compra no atacarejo. Dessa forma, todos os clientes que migraram a compra para o atacarejo atribuem ao fator preço o principal motivo. Dos clientes entrevistados, $38,04 \%$ classificam o fator preço como razoavelmente importante, dentre esses, $25 \%$ realizam suas compras somente no atacado, e $11,96 \%$ realiza a maior parte da compra no atacado.

O perfil do cliente e a classificação de importância do fator de entrega, entre os entrevistados, apontaram que $63,04 \%$ dos clientes consideram o fator de entrega como de extrema importância. Dentre os que consideram extremamente importante, $43,48 \%$ realizam suas compras apenas em atacado, e $18,48 \%$ realizam a maior parte da compra no atacado.

Dos entrevistados, $14,13 \%$ classifica a entrega como de pouca importância, e 13,04 classifica como nada importante. Entre esses entrevistados, todos realizam a maior parte da compra no atacarejo, em outras palavras, os clientes que compram no atacarejo não julgam a entrega como relevante na decisão de compra o fator entrega.

$\mathrm{Na}$ análise do perfil do cliente e da classificação de importância do prazo de pagamento na decisão de compra, $8,7 \%$ classificam como de extrema importância; dentro desses, $4,35 \%$ compram somente no atacado e a maior parte no atacado; $26,09 \%$ classificaam como importante, sendo que $20,65 \%$ compram somente no atacado; $4,35 \%$ compram a maior parte no atacado; e, 1,09\% realiza compras no atacado e no atacarejo.

Em meios aos entrevistados $31,52 \%$ classificm como pouco importante o prazo de pagamento. Dentro desses, $9,78 \%$ compram somente no atacado; $8,70 \%$ compram a maior parte no atacado; $13,04 \%$ compram a maior parte no atacarejo; e, 13,04\% dos entrevistados classificam como nada importante o fator de entrega e compram a maior parte no atacarejo.

Ao se fazer uma análise de perfil do cliente e a classificação da importância do fator fracionamento na decisão de compra, conclui-se que $25,00 \%$ classifica que é importante. Dentre estes, $22,83 \%$ compram a maior parte no atacarejo; $30,43 \%$ responderam como pouco e nada importante; e, dos últimos, $17,39 \%$ consideram pouco importante e compram somente no atacado, e, $21,74 \%$ classificam como nada importante a compra somente no atacado. 


\section{CONSIDERAÇÕES FINAIS}

O atacado vem evoluindo quanto à função de intermediário engajado nas vendas de bens para revenda ou para uso industrial. Pode ser considerado, além disso, como empresas que compram, adquirem direitos de propriedades, armazenam e revendem para seus clientes varejistas ou industriais, mantendo, assim, um estoque significante. Ainda, para atender em quantidades menores seus clientes, os varejistas, facilitam-Ihes a tarefa de selecionar e comprar os produtos que necessitam .

Outro canal de marketing que surge é o Atacarejo, considerado um novo formato de distribuição no mercado, que pode ser compreendido como uma loja que mistura as atividades de atacado e varejo. Este estudo pautou-se por verificar quais os fatores que levam pequenos e médios varejistas a optarem por migrar das compras dos atacados para o atacarejo.

Ao analisar as teorias sobre canais de marketing e sobre comportamento do consumidor, foi possível compreender que o varejo, em um mercado competitivo, pode redirecionar os pequenos varejistas e distribuidores a buscarem novas formas para realizarem suas compras.

$\mathrm{O}$ estudo evidenciou que os clientes como bares, restaurantes e padarias escolhem o atacarejo por terem, como fatores influenciadores, o melhor preço, o fracionamento e, ao mesmo tempo, a possibilidade de ter menor estoque, diminuindo, assim, seus custos de armazenagem. Também foi revelado que os clientes fazem a opção por atacadistas tradicionais, devido ao fato de estes apresentarem maior confiabilidade, melhor relacionamento, maior sortimento (marcas e linhas) de mercadorias e maior conveniência.

Os destaques referentes aos principais fatores que levaram os clientes à migração de compras de atacado para o atacarejo são apontados como sendo o preço e o fracionamento, consistindo em que $30,43 \%$ dos que fazem a maior parte das compras no atacarejo classifiquem como extremamente importante o fator de preço nas suas decisões de compra, e $22,82 \%$ dos que compram maior parte no atacarejo classifiquem como importante o fator fracionamento.

Já os clientes que compram somente ou a maior parte no atacado classificam o fator entrega, a conveniência, a confiança e a variedade como os fatores mais importantes na decisão de compra; $63,04 \%$ dos clientes consideram extremamente importante o fator de entrega, sendo que $43,48 \%$ compram somente no atacado, e $18,48 \%$ realiza a maior parte das suas compras no atacado. Assim, a conveniência e a confiança vêm a seguir nas classificações dos clientes. $60,87 \%$ e $56,32 \%$ leva esses fatores em consideração na decisão de compra como sendo os dois principais.

Finalmente, completando a sugestão para estudos futuros, pode-se ainda pensar em pesquisas dirigidas a outros segmentos, tais como atacadistas de frios e laticínios, atacadistas de ovos, café, entre outros, para verificar se os fatores aqui levantados para migrar suas compras do atacado para o atacarejo podem ser apontados como convergentes para esses distribuidores de outros segmentos. Uma limitação que merece ser considerada é a impossibilidade de ampla generalização desses esultados para todos os segmentos de distribuição, devido a amostra de conveniência feita neste trabalho. 


\section{REFERÊNCIAS BIBLIOGRÁFICAS}

AAKER, D. A.; KUMAR, V.; DAY, G. S. Pesquisa de marketing. São Paulo: Atlas, 2001. 745p.

ABAD - Associação Brasileira de Atacadistas e Distribuidores. Disponível em: <www.abad. com.br>. Acesso em: 11 Out. 2010.

ABRAS-AssociaçãoBrasileira deSupermercados. Disponível em: <www.abras.com.br>. Acesso em: 19 Out. 2010.

ALMEIDA, L. B. Estudo de um modelo conceitual de decisão, aplicado a eventos econômicos, sob a ótica da gestão econômica. 1996. 143 f. Dissertação (Mestrado) - Faculdade de Economia, Administração e Contabilidade da Universidade de São Paulo - USP.

AMA - Americam Marketing Association. Disponível em: <www.marketingpower.com>. Acesso em: 10 Abr. 2008.

ARNOLD, J. R. Tony. Administração de materiais. São Paulo: Atlas, 1999.

ASSAEL. H. Consumer behavior and Marketing Action. 4a Ed. Boston: PWS Kent, 1992.

BERMAN, B. Marketing Channels. Chichester: John Wiley \& Sons, 1996. 663 p.

BLACKWELL, R. D.; MINARD, P. W.; ENGEL, J. F. Comportamento do consumidor. 9a. ed. São Paulo: Pioneira Thomson Learning, 2005.

BOWERSOX, Donald J.; COOPER, Bixby. Strategic marketing channel management. $5^{a}$ ed., New York. Editora McGraw-Hill, 1992.

BRUGGEN, G. R. V. ; KACKER, M.; NIEUWLAAT, C. The Impact of Channel Function Performance on Buyer - Seller Relationship in Marketing Channels. Erasmus Research Institute of Management. p. 35. July, 2001.

BUCKLIN, L. P. A Theory of Distribution Channel Structure. Institute of business and economics: University of Berkley, 1996.

CHAVES, A. F. A. R. Estudo das variáveis utilizadas na decisão de compra no comércio varejista de alimentos de autosserviço supermercados. 2002. 206 f. Dissertação
(Mestrado em Contabilidade) - Faculdade de Economia, Administração e Contabilidade da Universidade de São Paulo,. USP. São Paulo.

CHURCHILL, G.; PETER, P. Criando valor para o cliente. São Paulo: Saraiva, 2000. 580p.

CONSOLI, Matheus Alberto. Análise da captura de valor nos canais de distribuição: utilização como ferramenta de auxílio ao planejamento de canais. 2005. 152 f. Dissertação (mestrado) - Faculdade de Economia, Administração e Contabilidade da Universidade de São Paulo USP.

COSTA, A. R.; TALARICO, E. G. Marketing promocional: descobrindo os segredos do mercado. São Paulo: Atlas, 1996.

COUGHLAN, A. T. et al. Canais de marketing e distribuição. 6.ed. Porto Alegre: Bookman, 2002. 461p.

DIAS, Sergio Roberto. Gestão de marketing. São Paulo : Saraiva, 2003. 539p.

Sergio Roberto. Estratégia e canais de distribuição. São Paulo: Atlas, 1993. 367p.

DONNELLY, Jr. James, H. Marketing Notes and Communications. Journal of Marketing. v. 40, p. $50-70$, Jan 1976.

ENGEL, J. F.; BLACKWELL, R. D.; MINIARD, P. W. Comportamento do Consumidor. 8.ed. Rio de Janeiro: LTC, 2000.

ETGAR, M.; ZUSMAN, P. The Marketing Intermediary as an Information Seller: a new approach. Journal of Business. V. 55, (4), p. $505-515$, cot. 1982.

FRAZIER, G. L.; LASSAR, W. M. Determinants of Distribution Intensity. Journal of Marketing. v. 60, (4), p. $39-51$. Oct. 1996.

GADE, C. Psicologia do Consumidor. São Paulo: Editora Pedagógica Universitária, 1980.

GIULIANI, Antônio Carlos. Marketing em um ambiente globalizado. São Paulo: Cobra, 2003a. 283p.

Gestão de marketing no varejo. São Paulo: OLM, 2003b. 254p. 
HAWKINS, D. I.; HAWKINS, BEST, R. J.; CONEY, K. A. Consumer Behavior: Bulding Marketing Strategy. 8th ed. Boston: Irwin/McGraw Hill, 2001.

HOWARD, J. A.; SHETH, J. N. The theory of buyer behavior. New York: John Wiley \& Sons, Inc., 1969.

KOTLER, P. Marketing para o século XXI: como criar, conquistar e dominar mercados. São Paulo: Futura, 1999.

. Adminstração de Marketing: Análise, Planejamento, Implantação e Controle. 5. ed. São Paulo: Atlas, 1998.

MALLEN, B. Selecting channels of distribution: a multi - stage process. International Journal of Physical Distribution \& Logistics Management. v.26, (5), p. $5-21,1996$.

MALHOTRA, N. Pesquisa de marketing: uma orientação aplicada. 3.ed. Porto Alegre: Bookman, 2001. 719p.

MEGIDO, Jose Luiz Tejon; SZULCSEWSKI, Charles John. Administração estratégica de vendas e canais de distribuição. São Paulo: Atlas, 2002. 168p.

MINOR, M. S.; MOWEN, J. C. Comportamento do Consumidor. São Paulo: Prentice Hall, 2003.

NEVES, M. F. Um Modelo para Planejamento de Canais de Distribuição no Setor de Alimento. 1999. 297 f. (Tese de Doutorado) - Faculdade de Economia, Administração e Contabilidade, Universidade de São Paulo, São Paulo, 1999.

PARENTE, J. Varejo no Brasil, gestão e estratégia. São Paulo: Atlas, 2000. 388p.

PRADO, K. P. L. A. A preferência da marca no processo de decisão de compra: um estudo exploratório no segmento de baixa renda. 2008. 323 f. (Tese de Doutorado) - Faculdade de Economia, Administração e Contabilidade, Universidade de São Paulo, São Paulo, 2008.

ROSENBLOOM, B. Canais de marketing: uma versão gerencial. São Paulo: Atlas, 2002. 437p.

SOUZA, M. G. Mercado de Consumo o presente e o future do varejo. São Paulo: Csfmd, 2009.
SOLOMON, M. R. 0 comportamento do consumidor: comprando, possuindo e sendo. 5.ed. Porto Alegre: Bookman, 2002.

SHETH, J. N.; MITTAL, B.; NEWMAN, B. I. Comportamento do cliente: Indo Além do Comportamento do Consumidor. Atlas, 2001.

STERN, L. W.; EL-ANSARY, A. I.; COUGHLAN, A. T. Marketing Channels. 5. ed, 1996, 576 p. 